Research Article

\title{
Experimental Research on Durability of Fly Ash Pavement Concrete and Mix Proportion Optimization
}

\author{
Hong-xia Zhai, ${ }^{1}$ Yu-zhao Tang, ${ }^{1}$ Shu-hang Chen, ${ }^{2}$ Hui-hua Chen $\left(\mathbb{D},{ }^{3}\right.$ Bao-quan Cheng $\mathbb{D}^{\circ}{ }^{3}$ \\ Xi Cai, ${ }^{3}$ and Yu-hu Wei ${ }^{1}$ \\ ${ }^{1}$ School of Materials and Chemical Engineering, Anhui Jianzhu University, Hefei 230601, China \\ ${ }^{2}$ School of Civil Engineering, Central South University, Changsha, Hunan 410075, China \\ ${ }^{3}$ Department of Civil Engineering, Xi'an Jiaotong-Liverpool University, Suzhou, Jiangsu 215123, China
}

Correspondence should be addressed to Bao-quan Cheng; curtis_ch@163.com

Received 12 September 2020; Revised 22 October 2020; Accepted 4 January 2021; Published 19 January 2021

Academic Editor: Erol Yilmaz

Copyright ( 92021 Hong-xia Zhai et al. This is an open access article distributed under the Creative Commons Attribution License, which permits unrestricted use, distribution, and reproduction in any medium, provided the original work is properly cited.

This paper focused on the optimization of the $\mathrm{C} 40 \mathrm{fly}$ ash concrete pavement, which was considered as a measure to accelerate the consumption of industrial solid wastes such as fly ash, committing to the goal of zero waste. By comparing with three groups of ordinary mix proportion, the performances (e.g., mechanical properties, durability, and brittle property) of the optimized mix proportion were evaluated via multiple mechanical and physical tests. Their air voids' structure was characterized by the $\mathrm{BJH}$ method (a method to calculate pore size described by Barrett, Joyner, and Halenda), and the results were combined with the road performances of concrete to analyze the formation mechanism of high durability of optimized fly ash pavement concrete. As for the experimental results for the optimized, its $28 \mathrm{~d}$ compressive strength peaked at $50.8 \mathrm{MPa}$ together with corresponding $28 \mathrm{~d}$ flexural strength at $8.2 \mathrm{MPa}$, which indicated a favorable mechanical performance for wide application in pavement construction. Except for the mechanical properties, the better durability indicators obtained after optimization also provided a more compact pore structure for the optimized. The raw materials and construction technology of the two kinds of pavements were compared. Promoting the use of optimized fly ash pavement concrete can break the situation of the asphalt pavement monopolizing heavyhaul highway and greatly reduce the industrial wastes which can be used as raw materials in the production of cement, such as blast furnace slag and fly ash. It was proved that the optimized fly ash concrete pavement can be used to replace the asphalt pavement under the premise of achieving the same working performances.

\section{Introduction}

Fly ash is the main solid waste discharged from coal-fired power plants. With the development of electric power industry, the emission of fly ash from coal-fired power plants is increasing year by year, which has become one of the industrial waste residues with large emission at present in China. The common method of use is to replace cement as concrete admixture. The concrete pavement is one of the main pavement types in China. Because of the rapid rise of asphalt price and the relative stability of cement price in recent years, using the concrete pavement can save a lot of investment compared with the asphalt pavement. It can also alleviate the oversupply of cement and stimulate local economy [1]. Therefore, promoting the concrete pavement has become the trend of traffic development. However, the concrete pavement was prone to early failure such as cracking and freezing erosion since insufficient attention is paid to the durability [2]. Especially, at present, with the rapid increasing number of vehicles in China, the damage of heavy vehicles to the concrete pavement is quite serious, which causes the real service life of some concrete pavement to fall less than the half of the designed cycle. Maintenance and reconstruction of the damaged concrete pavement cost a large amount of money and materials and meanwhile, generates many construction wastes. As a result, the proportion of the concrete pavement in high-grade highway was less than 10\% in China. Several provinces have even banned 
the use of concrete pavements in highways. Therefore, how to improve the durability of pavement concrete has become the focus of concrete research [3]. Fly ash referred to the tiny ash particles discharged during coal combustion and will cause serious air and water pollution without treatment. Some of the chemical ingredients will also pose negative impacts on the health of residents and other surrounding lives [4-6].

As an actively pozzolanic material, fly ash was considered for use in cementitious materials to replace part of cement, reducing the consumption of cement clinker and environmental impact. The amount of fly ash in concrete usually varies between $15 \%$ and $30 \%$ by content of the cementitious binders [7]. Higher replacement levels have also been used for large volume structures to decline the temperature rise in concrete. Studies show that although fly ash will adversely affect the early-age strength development of concrete $[8,9]$, it can improve the strength and durability of concrete at later ages by consuming $\mathrm{Ca}(\mathrm{OH})_{2}$ to generate secondary hydrates as C-S-H [9]. In addition, fly ash concrete also had a good performance in various types of structural systems. Although previous studies have proved that fly ash can improve the performance efficiently, most of them focused on fly ash concrete in buildings [10-13]. Research studies on the durability of fly ash pavement concrete were still limited. In 2013, Ondova et al. studied the potential use of fly ash as cement replacement in the concrete pavement by measuring mechanical properties, chemical resistance, freezing, and thawing of fly ash concrete, but failed to analyze the relationship between its microstructure and durability [14]. Later, most studies also just try to find the best mix ratio and design of fly ash concrete through experimental tests, but fail to interpret the relationship between durability and their pore structure combined with the road performance of the concrete pavement [15-18]. In addition, there were also many scholars at home and abroad contributing to exploring semiempirical formula for the relationship between strength and total porosity of cement-based materials. The deficiency was considering porosity as the only factor affecting the strength of concrete, without taking other pore structure parameters into account. Taking C40 pavement concrete as the research object, this paper comprehensively analyzed the effects of water-binder ratio and additives on the mechanical properties and durability of pavement concrete through orthogonal experimental data. The nitrogen adsorption method was introduced to characterize the pore structure of fly ash pavement concrete. Combined with the pore structure parameters, the mechanism of the pore structure on the strength, brittle property, and durability of fly ash pavement concrete was analyzed, respectively. The research provided scientific basis for the design method of fly ash pavement concrete mix proportion, which improved the service life of cement pavement concrete.

To address these research limits, this paper tried to improve the durability of concrete through the mix design. Under the premise of meeting the design and construction requirements, the water-binder ratio of concrete was reduced to reduce the porosity. Fly ash was used to replace part of cement to reduce the cement content of single concrete.
Proper amount of water reducer and air-entraining admixtures were applied to improve the impermeability and frost resistance of concrete, which improved the durability of concrete with ordinary strength. The objectives of this article were to overcome the difficulties in the wide application of ordinary concrete by optimizing the proportion of ordinary concrete, such as high brittle property and low durability. In addition, combined with the testing data and road performances, the relationship between pore structure and pavement durability was explained, and then, the mechanism analysis for improving pavement concrete after optimization was derived [19-21], aiming a solution towards zero waste and more ecological and friendly pavement design.

\section{Materials and Methods}

2.1. Materials. Ordinary Portland cement (P.O42.5R, $50.2 \mathrm{MPa}$ of $28 \mathrm{~d}$ compressive strength) was employed to prepare the C40 pavement concrete. Silica fume (SF) and fly ash (FA, Grade II, the main parameters are shown in Table 1) were selected as replacing parts of cement. Water reducer (polycarboxylic acid was the main ingredient, as shown in Table 2) was used to improve the product strength by reducing the water-binder ratio. River sand (the fineness modulus was 2.5) and gravel (particle size ranges from 5 to $31.5 \mathrm{~mm}$ ) were also used in this research. In addition, with the purpose to get favorable mechanical properties, other additives including air-entraining admixtures and reinforcing agent were applied.

2.2. Orthogonal Design of C40 Pavement Concrete. As specified in China, C40 cement concrete was widely used in concrete pavement construction. In this research, the designed strength grade of concrete was the C40 ordinary fly ash concrete pavement, which has D (serious) for environmental effect grade and $170 \mathrm{~mm}$ of the designed slump. In this section, the orthogonal design was carried out with the goal of getting the optimal mix proportion after the determination of the initial mix proportion, as shown in Table 3 ( $8 \%$ silica fume content and $1 \%$ compacting agent content). Then, the optimal mix proportion of C40 concrete was determined by analyzing the compressive strength, gas content, compressive strength, and flexural strength when the water-binder ratio $(A)$, water-reducer content $(B)$, fly ash content $(C)$, and amount of air-entraining admixtures $(D)$ were regarded as variables. The orthogonal experiment was designed according to the orthogonal table with four factors and three levels. The specific design and results of orthogonal experiments are shown in Tables 4 and 5, respectively.

\subsection{Methods}

2.3.1. Preparation of Pavement Concrete. According to GB/ T50081-2002, the one-time molding method and vibrating table were selected to mold the $150 \mathrm{~mm} \times 150 \mathrm{~mm} \times 150 \mathrm{~mm}$ cube and $150 \mathrm{~mm} \times 150 \mathrm{~mm} \times 550$ concrete prismoid for compressive strength and flexural strength testing, respectively. Then, the specimens were put in the standard curing 
Table 1: The main technical index of fly ash (\%).

\begin{tabular}{lccccccc}
\hline Alkali content & $\mathrm{SO}_{3}$ & $\mathrm{f}-\mathrm{CaO}$ & $\mathrm{CaO}$ & Activity index & Loss of burning & Water demand ratio & Fineness \\
\hline 0.45 & 0.2 & 0.03 & 4.43 & 84 & 1.01 & 94 \\
\hline
\end{tabular}

TABle 2: The main technical index of water reducer (\%).

\begin{tabular}{lccccc}
\hline Water reduction rate & Solid content & Density & Pressure bleeding rate & Gas content & $28 \mathrm{~d}$ shrinkage ratio \\
\hline 25.5 & 18.78 & 1.056 & 47 & 2.2 & 84 \\
\hline
\end{tabular}

TABLE 3: The initial mix proportion of C40 pavement concrete $\left(\mathrm{kg} / \mathrm{m}^{3}\right)$.

\begin{tabular}{lcccccccccc}
\hline$C$ & Fy & SF & $W$ & Sand & $\begin{array}{c}\text { Stone } \\
(5-10 \mathrm{~mm})\end{array}$ & $\begin{array}{c}\text { Stone } \\
(10-25 \mathrm{~mm})\end{array}$ & $\begin{array}{c}\text { Stone } \\
(25-31.5 \mathrm{~mm})\end{array}$ & $\begin{array}{c}\text { Polycarboxylic } \\
\text { acid }\end{array}$ & $\begin{array}{c}\text { Air-entraining } \\
\text { admixtures }\end{array}$ & $\begin{array}{c}\text { Compacting } \\
\text { agent }\end{array}$ \\
\hline 345.6 & 96.0 & 38.4 & 16 & 663 & 322.8 & 538 & 215.2 & 4.80 & 0.192 & 4.8 \\
\hline
\end{tabular}

TABle 4: The $\mathrm{L}_{9}\left(3^{4}\right)$ orthogonal factor level table.

\begin{tabular}{lcccc}
\hline Factor & N $(\%)$ & $B(\%)$ & $C(\%)$ & $D(\%)$ \\
\hline 1 & 0.33 & 0.6 & 15 & 0.08 \\
2 & 0.35 & 0.8 & 20 & 0.06 \\
3 & 0.37 & 1.0 & 25 & 0.04 \\
\hline
\end{tabular}

TABLE 5: Orthogonal design for the optimal mix proportion $\left(\mathrm{kg} / \mathrm{m}^{3}\right)$.

\begin{tabular}{cccccccccccc}
\hline No. & $C$ & FA & SF & $W$ & Sand & $\begin{array}{c}\text { Stone } \\
(5-10 \mathrm{~mm})\end{array}$ & $\begin{array}{c}\text { Stone } \\
(10-25 \mathrm{~mm})\end{array}$ & $\begin{array}{c}\text { Stone } \\
(25-31.5 \mathrm{~mm})\end{array}$ & $\begin{array}{c}\text { Water } \\
\text { reducer }\end{array}$ & $\begin{array}{c}\text { Air-entraining } \\
\text { admixtures }\end{array}$ & $\begin{array}{c}\text { Reinforcing } \\
\text { agent }\end{array}$ \\
\hline 1 & 301.5 & 112.5 & 36.0 & 167 & 663 & 322.8 & 538 & 215.2 & 4.50 & 0.360 & 4.5 \\
2 & 324.0 & 90.0 & 36.0 & 167 & 663 & 322.8 & 538 & 215.2 & 3.60 & 0.270 \\
3 & 346.5 & 67.5 & 36.0 & 167 & 663 & 322.8 & 538 & 215.2 & 2.70 & 0.180 \\
4 & 345.6 & 96.0 & 38.4 & 168 & 663 & 322.8 & 538 & 215.2 & 4.80 & 0.192 & 4.5 \\
5 & 369.6 & 72.0 & 38.4 & 168 & 663 & 322.8 & 538 & 215.2 & 3.84 & 0.384 & 4.8 \\
6 & 321.6 & 120.0 & 38.4 & 168 & 663 & 322.8 & 538 & 215.2 & 2.88 & 0.288 \\
7 & 385.0 & 75.0 & 40.0 & 165 & 663 & 322.8 & 538 & 215.2 & 5.00 & 0.030 & 4.8 \\
8 & 335.0 & 125.0 & 40.0 & 165 & 663 & 322.8 & 538 & 215.2 & 4.00 & 0.020 & 5.0 \\
9 & 360.0 & 100.0 & 40.0 & 165 & 663 & 322.8 & 538 & 215.2 & 3.00 & 0.040 & 5.0 \\
\hline
\end{tabular}

room with humidity greater than $95 \%$ and temperature $20 \pm 2^{\circ} \mathrm{C}$ to carry out the relevant test at the specified age.

2.3.2. Tests of Concrete Mixture. Referring to the methods specified in GB/T50080-2002 and GB8076-1997, properties of concrete mixtures (including slump and gas content) were tested. A slump cone (Figure 1) was used to measure the slump of concrete mixtures. The GQC-I modified method (Figure 2) was used to test the gas content of fresh concrete to reflect the frost resistance and number of pores in concrete.

\subsubsection{Durability Test of Concrete}

(1) Permeability. As shown in GB/T 50081-2002, the molding was carried out by the concrete mix proportion designed. After stirring for 3 minutes and vibrating the shaking table,

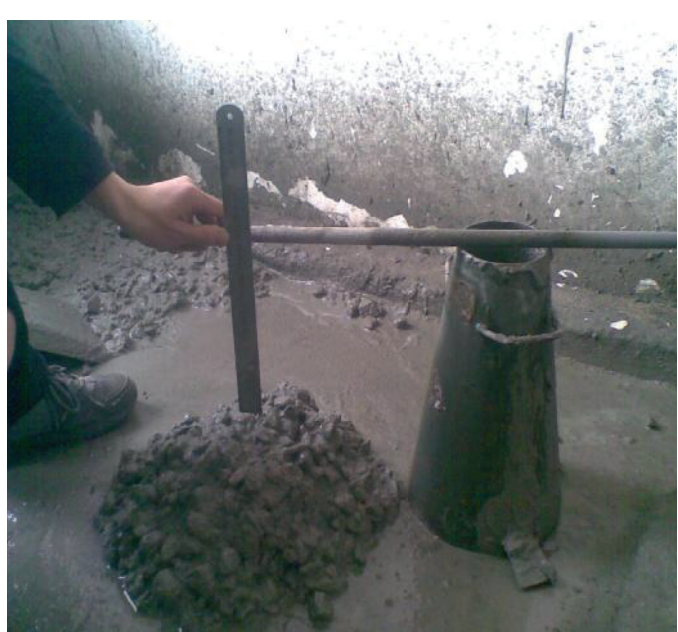

Figure 1: The slump test. 


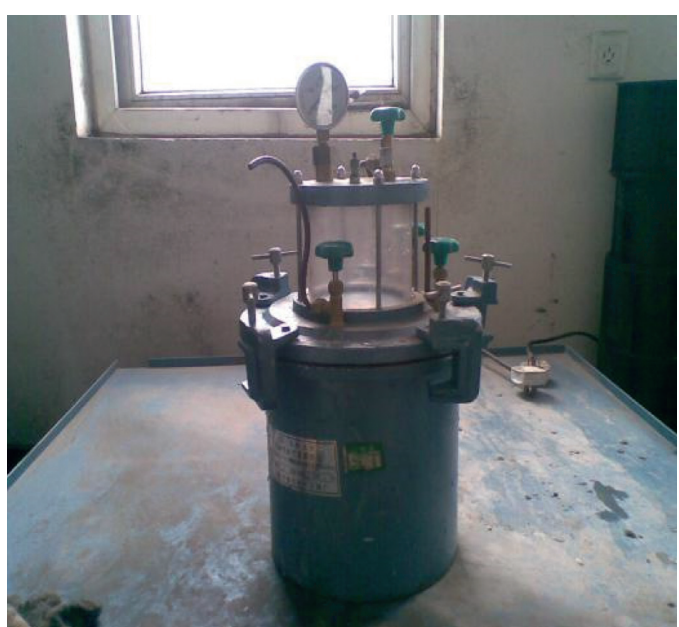

Figure 2: The gas content test.

six cylinder concrete specimens with $175 \mathrm{~mm}$ diameter of the top surface, $185 \mathrm{~mm}$ diameter of the bottom surface, and $150 \mathrm{~mm}$ height were formed as a group to be cured until the age. The water pressure started at $0.1 \mathrm{MPa}$ and raised by $0.1 \mathrm{MPa}$ at $8 \mathrm{~h}$ intervals. It was not until three of the six specimens were found to have seeped water on the surface that the test can be stopped to write down the water pressure at that time. The impervious grade of concrete was expressed as the maximum water pressure when four of the six specimens in each group have not been permeable. The formula is shown as follows:

$$
P=10 H-1,
$$

where $P$ is the impervious grade and $H$ is the water pressure in the three of the six specimens.

(2) Electric Flux. Referring to the ASTM C1202-97, the prepared test blocks were drilled core parts, and the end face was smoothed to make a cylinder of $\Phi 100 \mathrm{~mm} \times 50 \mathrm{~mm}$ before the specified curing age. Vacuum-saturated water was made for the specimen before the test. During the test, a $60 \mathrm{~V}$ DC voltage was added in the axial direction of the specimen. The solution with concentration of $0.3 \mathrm{~mol} / \mathrm{L}$ of $\mathrm{NaOH}$ and $3 \%$ of $\mathrm{NaCl}$ was placed in the test tank on both sides of the positive and negative electrodes of the specimen, respectively. The total electricity $Q$ value of the passing specimen within 6 hours was the electric flux of the specimen, and six specimens were a group. The test device is shown in Figure 3.

(3) Chloride Diffusion Coefficient. As the RCM method used by the Germany ibac-test, the $150 \mathrm{~mm} \times 150 \mathrm{~mm} \times 150 \mathrm{~mm}$ test specimen was made. The sample was taken from the standard curing room 4 days before the test. Then, the end face of samples was smoothed and was made into $\Phi 95 \mathrm{~mm} \times 50 \mathrm{~mm}$ test specimen (as shown in Figure 4) and put into the standard curing room to the test age. A $15 \mathrm{~min}$ ultrasonic bath was prepared for the specimen before the test. While the experiment proceeded, a $30 \mathrm{~V}$ DC voltage was applied to both ends of the specimen. The positive and negative electrodes of the specimen were dipped in $0.2 \mathrm{of} \mathrm{mol} / \mathrm{L} \mathrm{KOH}$

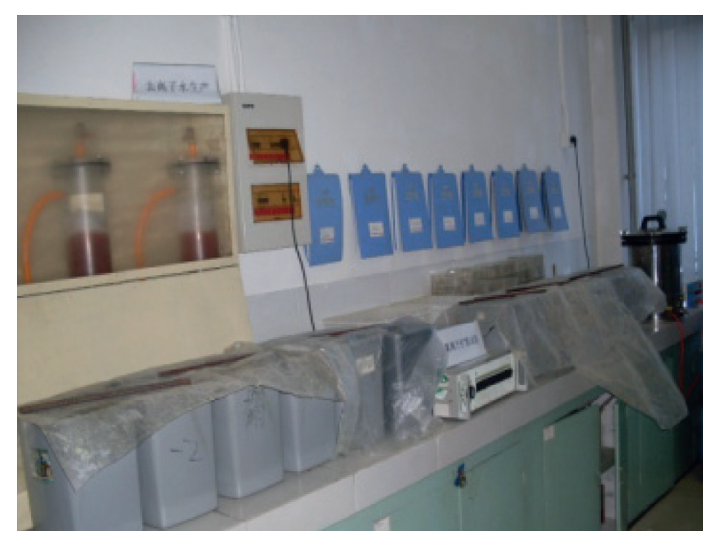

FIgure 3: The electric flux test.

solution and $5 \%$ of $\mathrm{NaCl}$ solution, respectively. The test device is shown in Figure 5, and the experimental period was determined by the initial current (as shown in Table 6). After electrification, the specimen was taken out and split into half on the hydraulic press machine, and $0.1 \mathrm{~mol} / \mathrm{L}$ of $\mathrm{AgNO}_{3}$ solution was sprayed on the surface of the split specimen. The chloride diffusion coefficient was tested by measuring the depth of chloride penetration and calculated. The formula for calculating chloride diffusion coefficient is as follows:

$$
\begin{aligned}
D_{\mathrm{RCM}} & =2.872 \times 10^{-6} \frac{\operatorname{Th}\left(x_{d}-\alpha \sqrt{x_{d}}\right)}{t}, \\
\alpha & =3.338 \times 10^{-3} \sqrt{T h},
\end{aligned}
$$

where $D_{\mathrm{RCM}}$ is the chloride diffusion coefficient $\left(\mathrm{m}^{2} / \mathrm{s}\right), T$ is the average of the initial and final temperature of the anode solution (Kessler's temperature), $h$ is the specimen height $(\mathrm{m}), x_{d}$ is chloride diffusion depth (m), $t$ is power-on time (s), and $\alpha$ is auxiliary variable.

(4) Flexural Elastic Modulus. The flexural elastic modulus of concrete was used to reflect the deformation capacity of concrete. As specified in JTG E30-2005, the test started with preloading from $1 \mathrm{kN}$ to $3 \mathrm{kN}$ at speeds of 0.15 to $0.25 \mathrm{kN} / \mathrm{s}$ and was held for $30 \mathrm{~s}$, and " 0 " was noted. Then, "0.5" was noted after continuing to load to $P_{0.5}$, which meant staying for $30 \mathrm{~s}$ under $50 \%$ of the bending limit. Five compressions were performed, and the fifth continuous load led to the specimen failure. The formula is as follows:

$$
E b=\frac{23 L^{3}\left(P_{0.5}-P_{0}\right)}{1296 J|0.5-0|}
$$

where $E b$ is the flexural elastic modulus (MPa), $P_{0.5}$ and $P_{0}$ represent end load and initial load $(\mathrm{kN}), 0.5$ and 0 are the thousands of meter readings corresponding to $P_{0.5}$ and $P_{0}$ $(\mathrm{mm}), L$ is the distance between specimen supports $(450 \mathrm{~mm}), J$ is the moment of inertia of specimen section $\mathrm{bh}^{3} / 12\left(\mathrm{~mm}^{4}\right)$, and $F$ is the midspan deflection $(\mathrm{mm})$.

2.3.4. Test of Pore-Size Distribution. As specified in GB/ T21650.2/ISO 15901-2:2006, the Autosorb-iQ automatic specific surface area and pore-size distribution instrument 


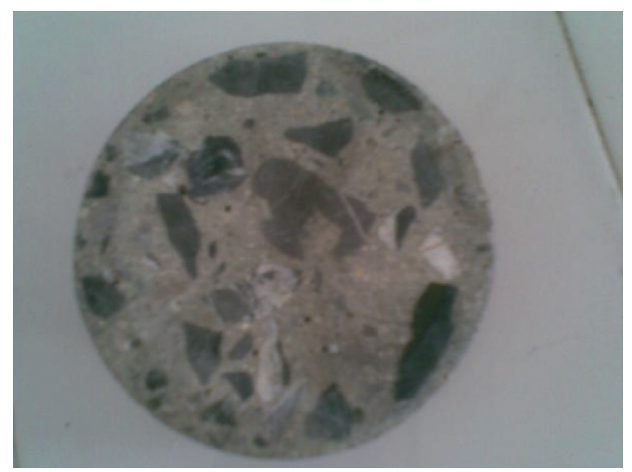

(a)

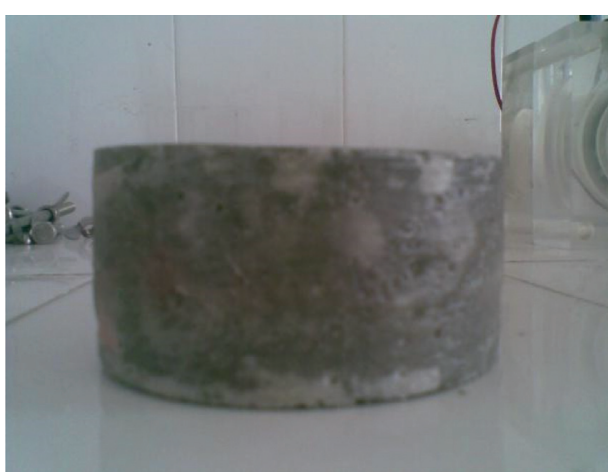

(b)

Figure 4: The antichlorine ion permeation test block.

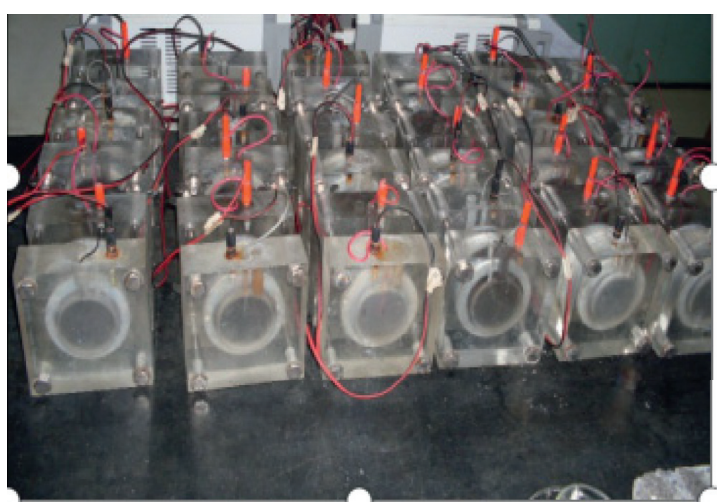

Figure 5: The chloride diffusion coefficient test.

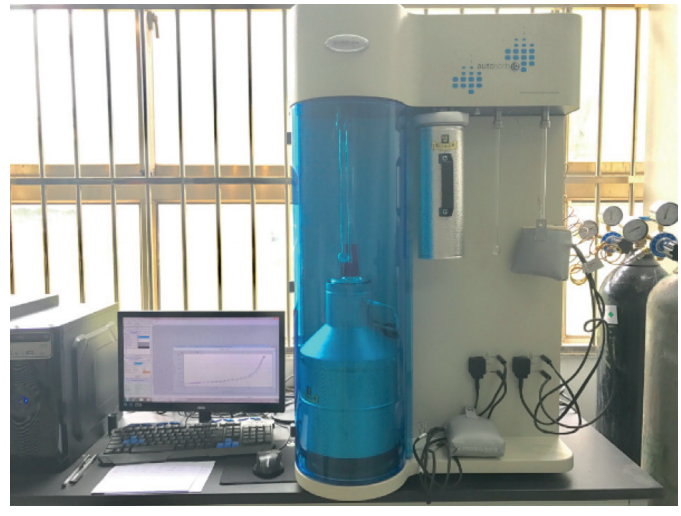

FIgURe 6: The Autosorb-iQ analyzer.
TABLE 6: The relationship between initial current and power-on time.

\begin{tabular}{lc}
\hline Initial current $I_{0}(\mathrm{~mA})$ & Power-on time $(\mathrm{h})$ \\
\hline$I_{0}<5$ & 168 \\
$5 \leq I_{0}<10$ & 96 \\
$10 \leq I_{0}<30$ & 48 \\
$30 \leq I_{0}<60$ & 24 \\
$60 \leq I_{0}<120$ & 8 \\
$120 \leq I_{0}$ & 4 \\
\hline
\end{tabular}

made by Quantachrome in America was used, and the working principle was the static capacity method with isothermal physical adsorption.

The sample was vacuumed continuously for $24 \mathrm{~h}$ at $100^{\circ} \mathrm{C}$ in advance to remove volatile substances. The sample mass was about $0.5 \mathrm{~g}$. The relative pressure was $0.00001 \sim 0.99800$ (111 points) and completed the desorption process. The minimum detection range of the gas adsorption isotherm method used in the study was the diameter of the gas molecules used, which can detect the open pores with pore size greater than $0.5 \mathrm{~nm}$. The $\mathrm{BJH}$ method, based on the Kelvin equation, was selected to calculate pore-size distribution. The range of its effective characterization is the mesoporousity over $2 \mathrm{~nm}$. Since Autosorb-iQ had two built-in degassing stations, the analysis and preparation of samples can be conducted at the same time, as shown in Figure 6.

\section{Results and Discussion}

3.1. The Results of the Orthogonal Design. Table 7 indicated that the compressive and flexural strength was generally relatively stable without much fluctuation. The average strength of groups with a water-binder ratio of 0.35 was just a little higher than other groups. On the contrary, the gas content of different groups varied a lot from $4.9 \%$ to $6.9 \%$. The range analysis of the orthogonal test was performed and is shown in Table 8 statistically. $K 1$ denoted average gas content for a certain variable at level 1 . By comparing and evaluating the index values at $K 1$, the optimal level of variables can be confirmed. The parameter $\Delta R$, as shown in Table 8 , indicated the effect of variables on gas content. A high $\Delta R$ value corresponding to a certain variable meant that this variable had a great effect on gas content.

The significance of each independent variable on the gas content was tested using ANOVA, as shown in Table 9. There were three threshold $F$ values corresponding to the three different levels of significance. The three different threshold values defined the significance of each independent variable in one of the four different categories (most significant: if the $F$ value is higher than 6.94; significant: if the $F$ value is between 4.32 and 6.93 ; less significant: if the $F$ value is between 4.32 and 6.93; least significant: if the $F$ value is lower than 2.00). It can be seen from Table 9 that airentraining admixtures had the highest impact on the gas 
TABLE 7: The results of orthogonal experiments.

\begin{tabular}{lcccccccc}
\hline \multirow{2}{*}{\begin{tabular}{c} 
No. Orthogonal combination \\
\cline { 3 - 7 }
\end{tabular}} & \multicolumn{4}{c}{ Assessment indicators } & \multicolumn{3}{c}{ Power coefficient } & \multirow{2}{*}{ Total power coefficient $d=\sqrt[3]{d_{1} d_{2} d_{3}}$} \\
\hline 1 & A1B1C1D1 & 6.9 & 28.9 & 1.92 & 0.710 & 0.963 & 0.861 & 0.847 \\
2 & A1B2C2D2 & 6.7 & 28.4 & 1.94 & 0.731 & 0.947 & 0.870 & 0.844 \\
3 & A1B3C3D3 & 5.4 & 28.7 & 1.97 & 0.907 & 0.957 & 0.883 & 0.915 \\
4 & A2B1C2D3 & 5.0 & 29.6 & 2.23 & 0.980 & 0.987 & 1.000 & 0.989 \\
5 & A2B2C3D1 & 6.3 & 29.8 & 2.13 & 0.778 & 0.993 & 0.955 & 0.904 \\
6 & A2B3C1D2 & 6.4 & 29.3 & 1.97 & 0.776 & 0.977 & 0.883 & 0.871 \\
7 & A3B1C3D2 & 6.0 & 29.1 & 1.98 & 0.870 & 0.970 & 0.889 & 0.890 \\
8 & A3B2C1D3 & 4.9 & 29.1 & 2.09 & 1.000 & 0.970 & 0.937 & 0.968 \\
9 & A3B3C2D1 & 6.1 & 30.0 & 1.95 & 0.803 & 1.000 & 0.874 & \\
\hline
\end{tabular}

${ }^{*} \mathrm{CS}$ : compressive strength; FS: flexural strength; $d_{1}$ : efficiency coefficient of gas content; $d_{2}: 3 \mathrm{~d}$ efficiency coefficient of compressive strength; $d_{3}: 3 \mathrm{~d}$ efficiency coefficient of flexural strength.

TABLE 8: The results of the extremum difference.

\begin{tabular}{lcccc}
\hline No. & Water-binder ratio & Water reducer $(\%)$ & Fly ash (\%) & Air-entraining admixtures $(\%)$ \\
\hline K1 & 6.33 & 5.97 & 6.07 & 6.43 \\
K2 & 5.9 & 5.97 & 5.93 & 6.37 \\
K3 & 5.67 & 5.97 & 5.9 & 5.1 \\
$\Delta R$ & 0.67 & 0 & 0.17 & 1.33 \\
Optimal & A2 & B1 & C2 & D3 \\
\hline
\end{tabular}

TABle 9: ANOVA for gas content.

\begin{tabular}{lcccccc}
\hline Independent variable & $\begin{array}{c}\text { Sum of } \\
\text { squares }\end{array}$ & $\begin{array}{c}\text { Degrees of } \\
\text { freedom }\end{array}$ & $F$ value & $P$ value & $\begin{array}{c}F \text { value at defined level of } \\
\text { significance }\end{array}$ & $\begin{array}{c}\text { Evaluation of } \\
\text { significance }\end{array}$ \\
\hline Water-binder ratio & 0.67 & 2 & 3.58 & 0.13 & 6.94 & 4.32 \\
Water reducer (\%) & $1.776^{*} 10^{-15}$ & 2 & $9.537^{*} 10^{-15}$ & 1.00 & 2.00 & Less significant \\
Fly ash (\%) & 0.042 & 2 & 0.22 & 0.67 & Least significant \\
Air-entraining & 2.67 & 2 & 14.32 & 0.02 & Least significant \\
admixtures (\%) & 0.74 & 2 & & & Most significant \\
Residual & 4.12 & 8 & & & \\
Total & & & & & \\
\hline
\end{tabular}

content of pavement concrete, followed by water-binder ratio, fly ash percentage, and water-reducer content. To make a sum, the optimum mix proportion of C40 fly ash pavement concrete is shown in Table $10[22,23]$.

\subsection{Performance of the Optimized Cement Pavement} Concrete. In order to further explore the working performance of the optimized C40 fly ash pavement concrete, the contrast experiments were carried out. The experimental design is shown in Table 11. The contrast experiments designed that the optimal mix proportion obtained by orthogonal experiments was compared to three groups of ordinary mix ratio under the conditions of equal strength and slump of design requirements. In this experiment, the $3 \mathrm{~d}, 7 \mathrm{~d}$, and $28 \mathrm{~d}$ compressive and flexural strength and other durability indicators were tested. Besides, the internal pore-size distribution of the optimal mix proportion concrete and ordinary one was characterized and summarized, so as to further account for the relationship between pore structure and mechanical properties and durability of the concrete.
3.2.1. Mechanical Properties. The flexural strength is a direct indicator to characterize the ability to resist bending of road. For pavement concrete, the national standard requires a flexural strength no less than $5 \mathrm{MPa}$ (specified in JTG D402011). However, even after meeting this minimum requirement, the application of the concrete pavement was still practically limited to certain locations. Moreover, although the durability of ordinary pavement concrete can conform to design requirements, its whole working performance could be still inefficient due to its irregular pore-size distribution. The mechanical properties are shown in Figure 7, and durability indicators' testing results can be seen in Table 12 . In contrast, the compressive and flexural strength of the optimal group were a little higher than that of other three groups. The impermeability grade of another three ordinary groups varied from P8 to P10, but the optimized C40 concrete reached at P10. Besides, it also possessed a lower chloride diffusion coefficient of $6.9^{*} 10^{-12} \mathrm{~m}^{2} / \mathrm{s}$ and a better electric flux of $1828 \mathrm{C}$. These results could be attributed to the favorable pore structure of the optimized concrete. The following experimental results can prove it. 
TABle 10: The optimal mix ratio of C40 pavement concrete $\left(\mathrm{kg} / \mathrm{m}^{3}\right)$.

\begin{tabular}{|c|c|c|c|c|c|c|c|c|c|c|}
\hline$C$ & Fly & SF & $W$ & Sand & $\begin{array}{c}\text { Stone } \\
(5-10 \mathrm{~mm})\end{array}$ & $\begin{array}{c}\text { Stone } \\
(10-25 \mathrm{~mm})\end{array}$ & $\begin{array}{c}\text { Stone } \\
(25-31.5 \mathrm{~mm})\end{array}$ & $\begin{array}{c}\text { Polycarboxylic } \\
\text { acid }\end{array}$ & $\begin{array}{l}\text { Air-entraining } \\
\text { admixtures }\end{array}$ & $\begin{array}{l}\text { Reinforcing } \\
\text { agent }\end{array}$ \\
\hline$\overline{345.6}$ & 96.0 & 38.4 & 168 & 663 & 322.8 & 538 & 215.2 & 4.80 & 0.192 & 4.8 \\
\hline
\end{tabular}

TABLe 11: The contrast mix proportion of C40 pavement concrete.

\begin{tabular}{lcccc}
\hline Group & Water-binder ratio & Fly ash $(\%)$ & Water reducer (\%) & Air-entraining admixtures (\%) \\
\hline 1 & 0.37 & 15 & 0.5 & 0.06 \\
2 & 0.38 & 25 & 0.4 & 0.08 \\
3 & 0.41 & 20 & 0.7 & 0.09 \\
Optimal & 0.35 & 20 & 1.0 & 0.04 \\
\hline
\end{tabular}

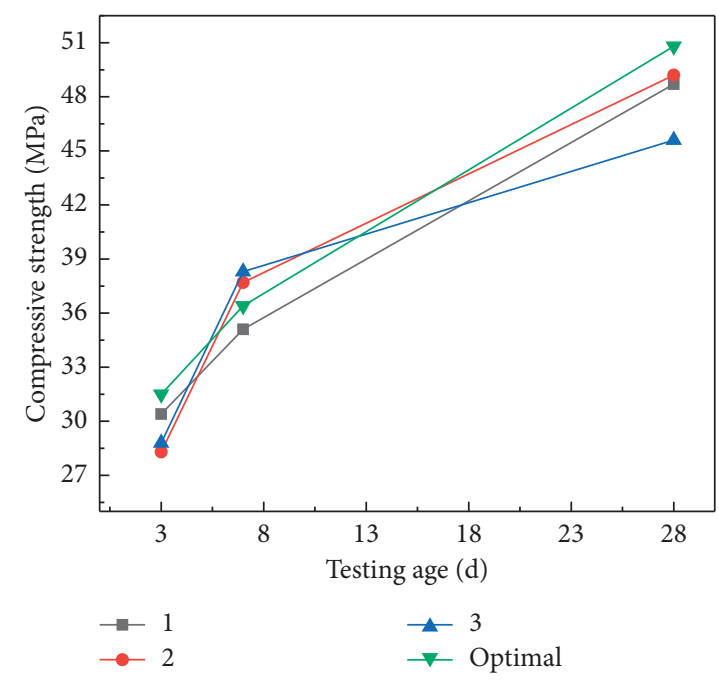

(a)

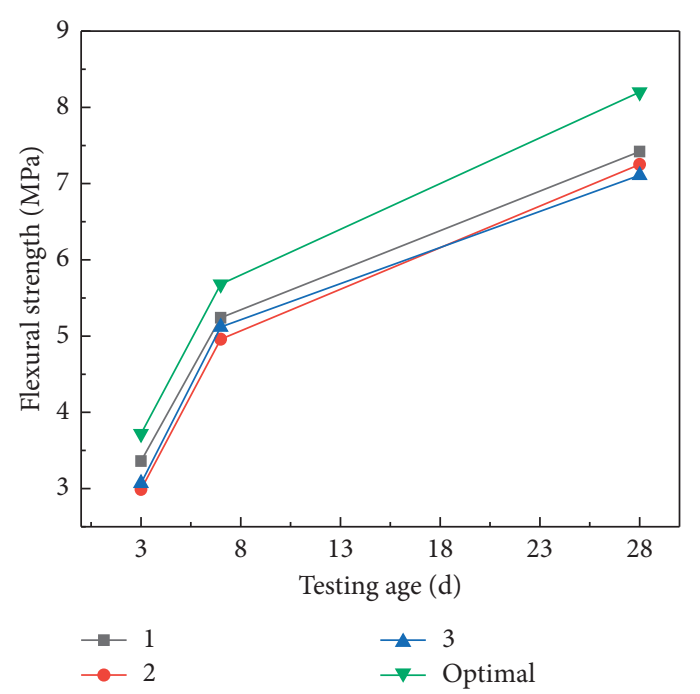

(b)

FIGURE 7: Mechanical properties of the contrast groups.

TABLE 12: The durability of contrast groups.

\begin{tabular}{lccc}
\hline Group & $\begin{array}{c}\text { Durability } \\
\text { Impermeability } \\
\text { grade }\end{array}$ & $\begin{array}{c}D_{\mathrm{RCM}} \\
\left({ }^{*} 10^{-12} \mathrm{~m}^{2} / \mathrm{s}\right)\end{array}$ & $\begin{array}{c}\text { Electric flux } \\
(\mathrm{c})\end{array}$ \\
\hline 1 & P10 & 8.0 & 2218 \\
2 & P8 & 8.4 & 2399 \\
3 & P10 & 8.9 & 2436 \\
Optimal & P12 & 6.9 & 1828 \\
\hline
\end{tabular}

In the section of the concretes, as shown in Figures 8 and 9 , the bubbles forming in the concrete with ordinary mix proportion were larger and relatively concentrated, which directly led to the reduction of the compactness of the concrete. By analyzing the data in Table 11 and Figure 7, we can find that the content of air-entraining admixtures in the ordinary mix proportion was higher than that of the optimal group, resulting in higher gas content. Due to the introduction of too many bubbles, some internal bubbles connected with each other, contributing to the loss of mechanical properties. Combined with the results of the

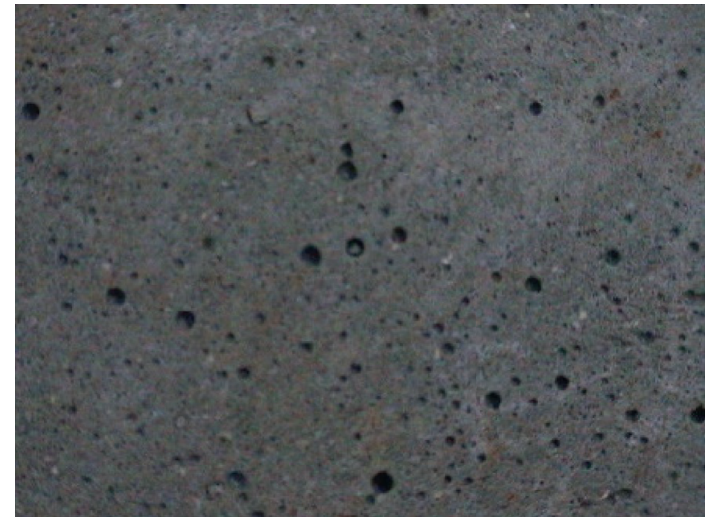

FIGURE 8: The section of optimal proportion.

extremum difference from the orthogonal experiments above, when reducing the content of air-entraining admixtures, the ordinary pavement concrete can get optimized by reasonably controlling the content of other additives to possess a homogeneous pore structure of concrete. 


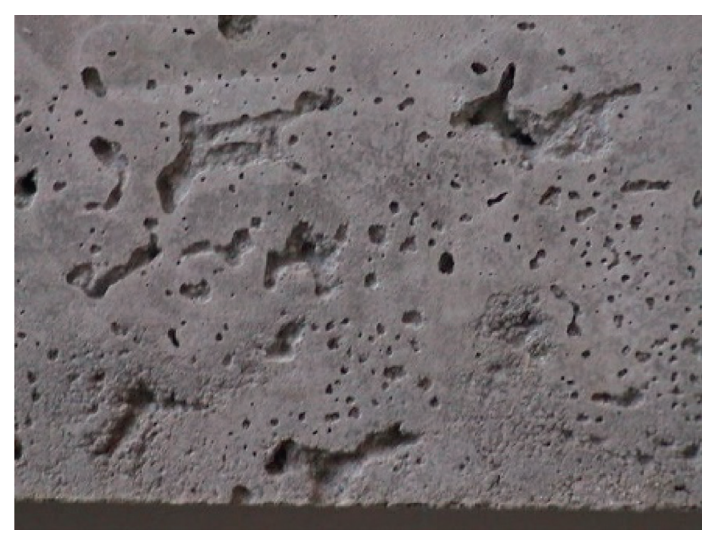

FIGURE 9: The section of ordinary proportion.

3.2.2. Durability. Concrete was a typical porous material with complex pore-size distribution. The span of pore size crossed between microscale and macroscale, which had great influence on the mechanical properties and durability of concrete. The permeability and carbonation resistance of concrete seriously affected the durability of the structure. The pores and capillary channels connected inside the concrete were the main reasons for the decrease of impermeability, and the pore-size distribution also had a great influence on the antipermeability. Mehta [24] divided the pores into four grades according to pore size $(d): d<20 \mathrm{~nm}$ as harmless pores; $d=20-50 \mathrm{~nm}$ as less harmful pores; $d=50-100 \mathrm{~nm}$ as harmful pores; $d>100 \mathrm{~nm}$ as multihazard pores. Obviously, the cementitious pores belonged to the category of harmless pores and have no effect on the durability, impermeability, and strength of concrete. The pore size changed greatly because of the difference of the watercement ratio and hydration degree, which can be divided into less harmful pores, harmful pores, and multihazard pores, which will seriously harm the permeability and durability of concrete. As for the effect of pores in concrete on durability, the literature introduced a comprehensive damage model under external (environmental) and internal factors, which described the process that pores developed and eventually led to the cracking and collapse of concrete [25-29].

The test results of pore structure are shown in Figures 10 and 11 . Based on the pore-size distribution, nearly $80 \%$ of the pores in the optimized pavement concrete were smaller than $20 \mathrm{~nm}$, which provided a more compact pore structure for it. In contrast, the pores with radius more than $20 \mathrm{~nm}$ in the ordinary group were over twice as much as that in the optimized group. This result caused the increase of pore connectivity and permeability of the ordinary pavement concrete due to climate and load effects, which led to the ability of pore structure to resist the penetration of external forces decreasing, thus making the overall working performance decline [30-35].

3.2.3. Analysis on Brittle Property of the Optimized Pavement Concrete. Compared with other concretes, the failure of pavement concrete was caused by flexible-tensile stress, and the flexural strength of concrete was much lower than compressive strength. When the tensile stress of concrete cannot withstand the vertical stress of load, horizontal impact, and the tensile stress caused by chemical shrinkage and temperature deformation, the concrete appeared to have cracks. Therefore, low brittle property was greatly beneficial to pavement concrete.

Due to the limitation of raw materials, construction technology, and so on, there are a large number of microcracks and inhomogeneous pores in the concrete. The internal structure showed extreme complexity, and it was relatively difficult to improve the brittle property of pavement concrete. Scholars at home and abroad had carried out a lot of research studies on the brittleness of concrete. In essence, effective methods can be found to improve the brittle property of concrete, such as improving its pore structure, reducing internal microcracks, and controlling the cracking and expansion of microcracks during failure. Macroscopically, the brittle property of concrete can be improved by raw materials, mix ratio, construction technology, and so on.

At present, there was no uniform standard for measuring the brittle property of concrete. The compression-flexure ratio and flexural elastic modulus of pavement concrete were regarded as the commonly used indexes in engineering circles. The brittleness coefficient of concrete represented by the compression-flexure ratio reflected the antideformation performance of concrete. The smaller the brittleness coefficient was, the better the antideformation ability was. The above two indexes were tested and calculated in this research, and the results are shown in Figure $12[36,37]$.

It can be seen from the testing results that the compression-flexure ratio decreased with the increase of trial age, and the rate of increase of flexural strength was higher than that of compressive strength. The concrete with the optimum ratio possessed a smaller compression-flexure ratio, which contributed to its higher strength and flexibility than ordinary concrete. On the contrary, the optimum proportion of pavement concrete had higher flexural modulus than ordinary concrete, which achieved lower brittle property and improved the durability of pavement concrete to a degree.

\subsubsection{Formation Mechanism of High Durability of Optimized} Pavement Concrete. The durability of concrete was a kind of ability that makes it resist climate change, chemical erosion, abrasion, or any other destruction process. For pavement concrete, because of the uncovered exposure to the atmosphere and long-term erosion by the external environment, the pavement structure would suffer damage. Excellent durability not only was an important guarantee for design service life of the concrete pavement but also can reduce the difficult maintenance of the cement concrete pavement and avoid investing a large amount of reconstruction or overlay cost, which was also of great significance to realize the sustainable development of national economy. The formation mechanism of the optimized pavement concrete of high durability was analyzed from the following three aspects: 


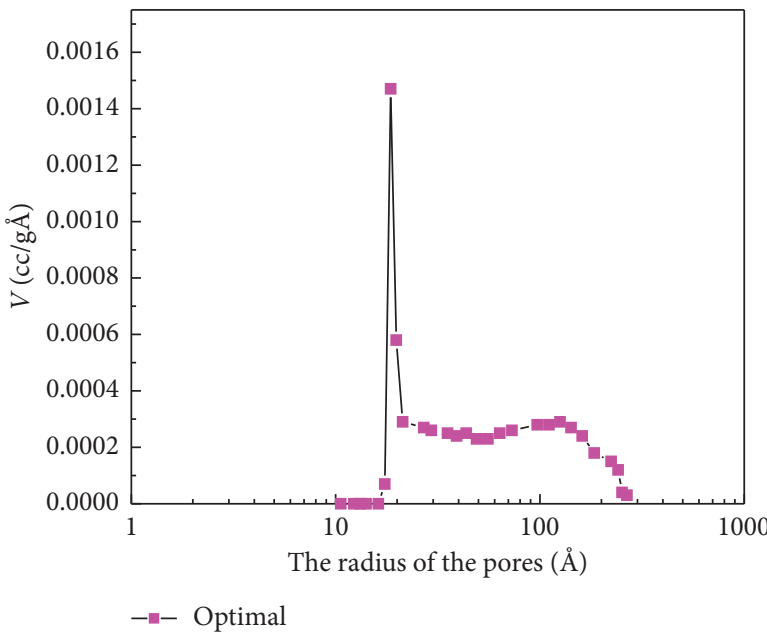

(a)

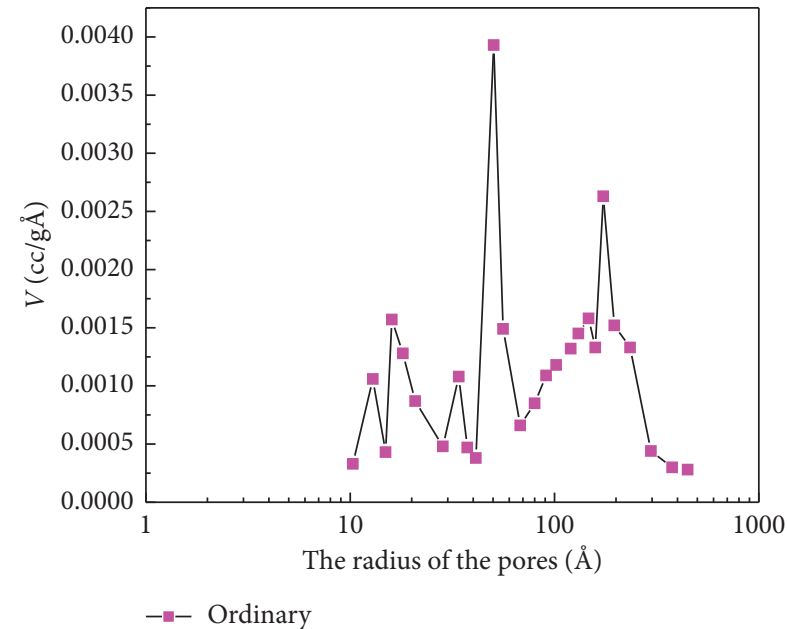

(b)

FIgURE 10: Desorption pore-volume distribution by the BJH method.

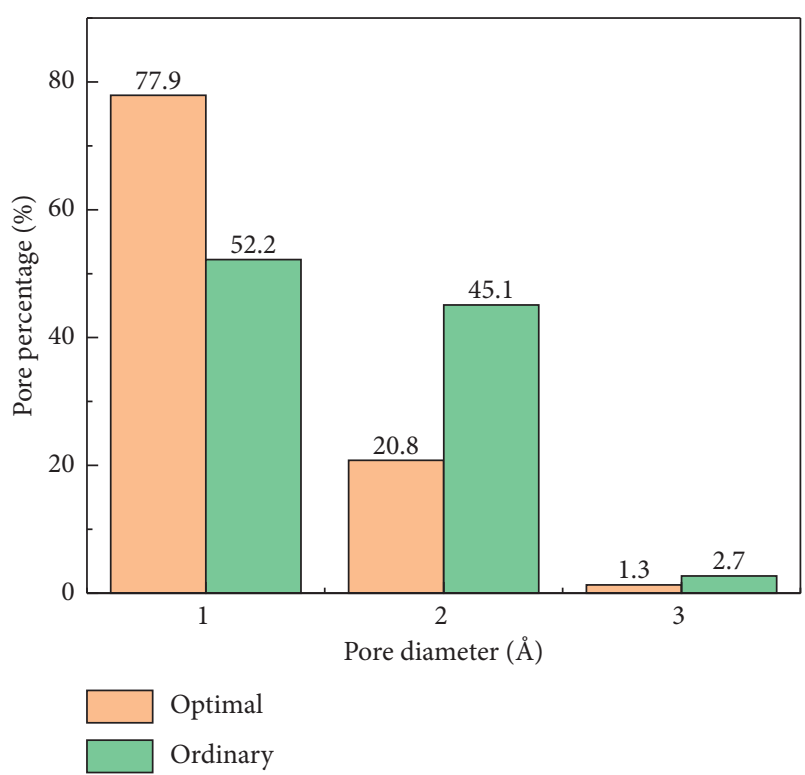

FIgURE 11: The results of pore-size distribution.

(1) The Optimization of Pore Structure Features. Concrete is composed of cement stone, aggregate, and interface, all of which had pores that were the channel of ion permeation. The pore characteristics of concrete determine that the erosion ions generally permeated from the interface into the cement stone. The products of the concrete additive involved in the hydration reaction, and its unreacted fine particles can fill the capillary pores of the cement stone, which makes concrete more compact. With the development of hydration age, the harmful macropores in the optimized concrete decreased and the harmless or less harmful pores or micropores increased, which meant that pore structure and frost resistance of the optimized pavement concrete were improved.

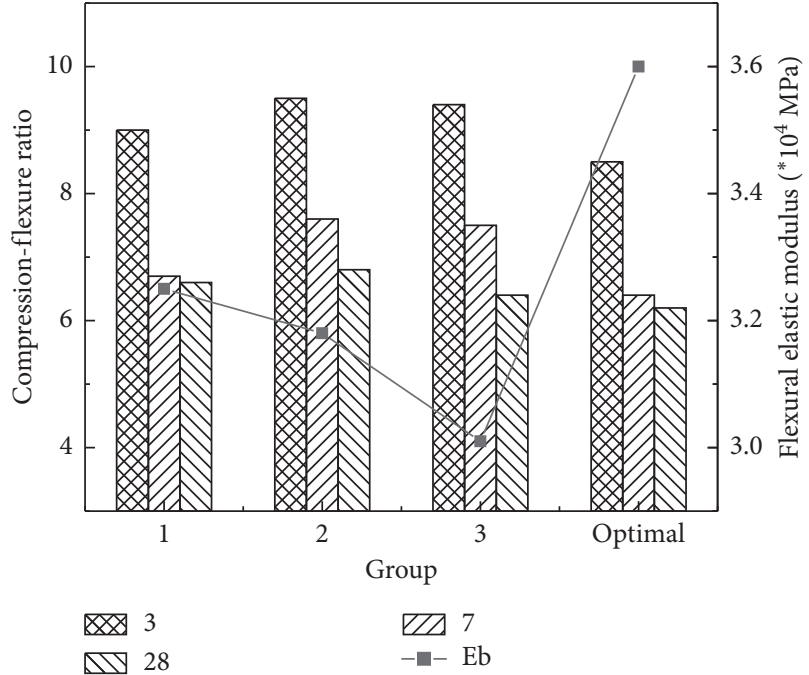

Figure 12: The brittle property of optimized pavement concrete.

(2) The Enhancement of Interface Transition Zone. With the addition of water reducer, the optimized concrete can obtain lower water-to-glue ratio, which enhanced the strength and elastic modulus of cement stone. Given this, the gap between cement stone and elastic modulus of aggregate was cut down, which made the thickness of the water film layer at the interface decrease, and the free space for crystal growth reduced. Additionally, silica fume and other mineral additives reacted in the interface area, leading to more C-S-H and AFt and less $\mathrm{CH}$ in the interface. The crystallization of the hydrates was also interfered, which resulted in the size of the crystalline particles of the hydrates getting smaller and the degree of enrichment and orientation going down. Finally, the interfacial transition zone achieved improvement, thus cutting off the channel of erosive permeation along the interface [38]. 
(3) The Hard Corrosion of Steel Bar. The corrosion condition of reinforcement in concrete was that the $\mathrm{pH}$ value of pore solution was less than 11.5 or the $\mathrm{Cl}^{-} / \mathrm{OH}^{-}$ratio was greater than 0.63 . (1) The fly ash had little effect on the liquid alkalinity of concrete and mainly absorbed the $\mathrm{K}^{+}$and $\mathrm{Na}^{+}$in the pore solution. Its $\mathrm{OH}^{-}$concentration suffered very little effect, so its $\mathrm{pH}$ value remained over 12.0; (2) the chloride diffusion coefficient of the optimized concrete was small $\left(D_{\mathrm{RCM}}=6.9 \times 10^{-12} \mathrm{~m}^{2} / \mathrm{s}\right)$, and most of the $\mathrm{Cl}^{-}$were united during diffusion. Therefore, the free $\mathrm{Cl}^{-}$at the steel bar interface was very few, which was not enough to destroy the passivation film [39-41].

\section{Conclusions}

In this paper, the optimized mix proportion was obtained from the orthogonal tests, which was compared to the ordinary concrete by evaluating the mechanical properties, durability, brittle property, and pore structure. Then, based on the results of contrast tests, the relationship between the concrete durability and pore structure was discussed, and the formation mechanism of high durability of optimized pavement concrete was further explained. The main conclusions about optimized C40 concrete performance were drawn as follows:

(i) The optimized product based on the optimal mix ratio obtained from the orthogonal experiments possesses $50.8 \mathrm{MPa}$ of $28 \mathrm{~d}$ compressive strength and $8.2 \mathrm{MPa}$ of $28 \mathrm{~d}$ flexural strength.

(ii) The durability indexes are summarized as the following: P12 of impermeability grade, $1828 \mathrm{c}$ of $28 \mathrm{~d}$ electrical flux, and $6.9 \times 10^{-12} \mathrm{~m}^{2} / \mathrm{s}$ of chloride diffusion coefficient. Results indicated a favorable performance for wide application in pavement engineering.

(iii) The flexural elastic modulus reached $3.6 \times 10^{4} \mathrm{MPa}$, which achieved the goal of low brittleness through the analysis of the compression-flexure ratio.

(iv) The internal pore-size, respectively, showed that the number of less harmful pores $(d=20-50 \mathrm{~nm})$ in the ordinary proportion was $24.2 \%$ more than that in the optimal group, and the number of harmless pores $(d<20 \mathrm{~nm})$ was $25.7 \%$ less than that in the optimal group, which proved that the pore structure of the optimized pavement concrete became more compact.

\section{Data Availability}

The data used to support the findings of this study are included within the article.

\section{Conflicts of Interest}

The author declares that there are no conflicts of interest regarding the publication of this paper.

\section{Authors' Contributions}

H. Zhai, B. Cheng, S. Chen, and H. Chen conceptualized the study and developed research design; Y. Tang, B. Cheng,
S. Chen, and H. Chen developed experiment design; Y. Tang, H. Zhai, S. Chen, B. Cheng, and X. Cai carried out experiment test; S. Chen, Y. Tang, and X. Cai analyzed the data; Y. Tang, B. Cheng, H. Zhai, and S. Chen wrote the original article; H. Zhai, Y. Tang, and Y. Wei revised and edited the article; Y. Wei carried out proofing; H. Zhai and H. Chen helped in funding.

\section{Acknowledgments}

This work was supported by Natural Science Found Foundation of Anhui Province (no. 2008085QE246), Ph.D. initial funding of Anhui Jianzhu University (no. 2019QDZ15), and Department of Housing and Urban-Rural Development of Anhui Province Funded Projects (no. 2018FACN3476).

\section{References}

[1] S. Pranav, S. Aggarawal, E. H. Yang et al., "Alternative materials for wearing course of concrete pavements: a critical review," Construction and Building Materials, vol. 236, Article ID 117609, 2020.

[2] E. Holt and M. Leivo, "Cracking risks associated with early age shrinkage," Cement and Concrete Composites, vol. 26, no. 5, pp. 521-530, 2004.

[3] M. V. Mohod and K. N. Kadam, "A comparative study on rigid and flexible pavement: a review," IOSR Journal of Mechanical and Civil Engineering, vol. 13, pp. 84-88, 2016.

[4] C. Belviso, F. Cavalcante, S. Palma, P. Ragone, and S. Fiore, "Mobility of trace elements in fly ash and in zeolitised coal fly ash,” Fuel, vol. 144, pp. 369-379, 2015.

[5] W. Müllauer, R. E. Beddoe, D. Heinz et al., "Leaching behaviour of major and trace elements from concrete: effect of fly ash and GGBS," Cement and Concrete Composites, vol. 58, pp. 129-139, 2015.

[6] H. Wang, Y. Wu, M. Wei, L. Wang, and B. Cheng, "Hysteretic behavior of geopolymer concrete with active confinement subjected to monotonic and cyclic axial compression: an experimental study," Materials, vol. 13, no. 18, p. 3997, 2020.

[7] M. Thomas, "Optimizing the use of fly ash in concrete," Skokie, IL: Portland Cement Association, vol. 5420, 2007.

[8] A. B. Harwalkar and S. S. Awanti, "Laboratory and field investigations on high-volume fly ash concrete for rigid pavement," Transportation Research Record: Journal of the Transportation Research Board, vol. 2441, no. 1, pp. 121-127, 2014.

[9] Y. Kocak and S. Nas, "The effect of using fly ash on the strength and hydration characteristics of blended cements," Construction and Building Materials, vol. 73, pp. 25-32, 2014.

[10] S. Altoubat, M. Talha Junaid, M. Leblouba, and D. Badran, "Effectiveness of fly ash on the restrained shrinkage cracking resistance of self-compacting concrete," Cement and Concrete Composites, vol. 79, pp. 9-20, 2017.

[11] N. Chousidis, I. Ioannou, E. Rakanta, C. Koutsodontis, and G. Batis, "Effect of fly ash chemical composition on the reinforcement corrosion, thermal diffusion and strength of blended cement concretes," Construction and Building Materials, vol. 126, pp. 86-97, 2016.

[12] N. Chousidis, E. Rakanta, I. Ioannou, and G. Batis, "Mechanical properties and durability performance of reinforced concrete containing fly ash," Construction and Building Materials, vol. 101, pp. 810-817, 2015. 
[13] K. Cox and N. D. Belie, "Durability behavior of high-volume fly ash concrete," in Proceedings of the 2007 Internationl Conference Sustainable Construction Materials and Technologies, Coventry, UK, 2007.

[14] M. Ondova, N. Stevulova, L. Meciarova et al., "The potential of higher share of fly ash as cement replacement in the concrete pavement," Procedia Engineering, vol. 65, pp. 45-50, 2013.

[15] S.-W. Yoo, G.-S. Ryu, J. F. Choo et al., "Evaluation of the effects of high-volume fly ash on the flexural behavior of reinforced concrete beams," Construction and Building Materials, vol. 93, pp. 1132-1144, 2015.

[16] S. A. Kristiawan and M. T. M. Aditya, "Effect of high volume fly ash on shrinkage of self-compacting concrete," Procedia Engineering, vol. 125, pp. 705-712, 2015.

[17] X. Wang, Y. B. Wang, L. S. Yang et al., "High-performance, high-volume fly ash concrete," Bulletin of the Chinese Ceramic Society, vol. 32, pp. 523-522, 2013.

[18] Z. H. Wang, L. Li, Y. X. Zhang et al., "Bond-slip model considering freeze-thaw damage effect of concrete and its application," Engineering Structures, vol. 201, Article ID 109831, 2019.

[19] H. Zhao, X. Qin, J. Liu, L. Zhou, Q. Tian, and P. Wang, "Pore structure characterization of early-age cement pastes blended with high-volume fly ash," Construction and Building $\mathrm{Ma}$ terials, vol. 189, pp. 934-946, 2018.

[20] C. Lian, Y. Zhuge, and S. Beecham, "The relationship between porosity and strength for porous concrete," Construction and Building Materials, vol. 25, no. 11, pp. 4294-4298, 2011.

[21] X. Chen, S. Wu, and J. Zhou, "Influence of porosity on compressive and tensile strength of cement mortar," Construction and Building Materials, vol. 40, pp. 869-874, 2013.

[22] Y. Xu, R. Jin, L. Hu et al., "Studying the mix design and investigating the photocatalytic performance of pervious concrete containing $\mathrm{TiO}_{2}$-soaked recycled aggregates," Journal of Cleaner Production, vol. 248, Article ID 119281, 2020.

[23] H. Chen, H. li, Y. Wang, and B. Cheng, "A comprehensive assessment approach for water-soil environmental risk during railway construction in ecological fragile region based on AHP and MEA," Sustainability, vol. 12, no. 19, p. 7910, 2020.

[24] P. K. Mehta, "Durability of concrete-fifty years of progress," in Proceedings of the 2nd International Conference on Durability of Concrete, Montreal, Canada, 1991.

[25] H. Y. Moon, H. S. Kim, and D. S. Choi, "Relationship between average pore diameter and chloride diffusivity in various concretes," Construction and Building Materials, vol. 20, no. 9, pp. 725-732, 2006.

[26] J. J. Beaudoin and V.S. Ramachandran, "A new perspective on the hydration characteristics of cement phases," Cement and Concrete Research, vol. 22, no. 4, pp. 689-694, 1992.

[27] Z.-H. Wang, L. Li, Y.-X. Zhang, and S.-S. Zheng, "Reinforcement model considering slip effect," Engineering Structures, vol. 198, Article ID 109493, 2019.

[28] Y. Guo, Z. Chen, X. Qin, A. Shen, S. Zhou, and Z. Lyu, "Evolution mechanism of microscopic pores in pavement concrete under multi-field coupling," Construction and Building Materials, vol. 173, pp. 381-393, 2018.

[29] M. A. Vicente, D. C. González, J. Tarifa, G. Ruiz, and R. Hindi, "Influence of the pore morphology of high strength concrete on its fatigue life," International Journal of Fatigue, vol. 112, pp. 106-116, 2018.

[30] B. Q. Cheng, H. L. Wang, L. Wang et al., "The study on the whole stress-strain curves of coral fly ash-slag alkali-activated concrete under uniaxial compression," Materials, vol. 13, p. $4291,2020$.
[31] D. N. Winslow, M. D. Cohen, D. P. Bentz, K. A. Snyder, and E. J. Garboczi, "Percolation and pore structure in mortars and concrete," Cement and Concrete Research, vol. 24, no. 1, pp. 25-37, 1994.

[32] B. B. Das and B. Kondraivendhan, "Implication of pore size distribution parameters on compressive strength, permeability and hydraulic diffusivity of concrete," Construction and Building Materials, vol. 28, no. 1, pp. 382-386, 2012.

[33] Y. Yang, T. Zhao, H. Jiao, Y. Wang, and H. Li, "Potential effect of porosity evolution of cemented paste backfill on selective solidification of heavy metal ions," International Journal of Environmental Research and Public Health, vol. 17, no. 3, p. 814, 2020.

[34] B. Cheng, J. Li, V. W. Y. Tam, M. Yang, and D. Chen, “A BIMLCA approach for estimating the greenhouse gas emissions of large-scale public buildings: a case study," Sustainability, vol. 12 , no. 2 , p. $685,2020$.

[35] H. Z. Jiao, S. F. Wang, A. X. Wu et al., "Cementitious property of $\mathrm{NaAlO}_{2}$-activated Ge slag as cement supplement," International Journal of Minerals, Metallurgy and Materials, vol. 26, no. 182, pp. 112-121, 2019.

[36] S. B. Zhou, A. Q. Shen, X. Li et al., "A relationship of mesoscopic pore structure and concrete bending strength," Materials Research Innovations, vol. 19, 2016.

[37] A. Shen, S. Lin, Y. Guo, T. He, and Z. Lyu, "Relationship between flexural strength and pore structure of pavement concrete under fatigue loads and freeze-thaw interaction in seasonal frozen regions," Construction and Building Materials, vol. 174, pp. 684-692, 2018.

[38] S. Yang, X. Zhongzi, X. Ping, and T. Mingshu, “A new method of enhancing cement-aggregate interfaces II. Mechanical properties and sulphate attack resistances of mortars," Cement and Concrete Research, vol. 22, no. 5, pp. 769-773, 1992.

[39] M. Ormellese, M. Berra, F. Bolzoni et al., "Corrosion inhibitors for chlorides induced corrosion in reinforced concrete structures," Cement and Concrete Research, vol. 36, no. 3, pp. 536-547, 2006.

[40] A. Scott and M. G. Alexander, "Effect of supplementary cementitious materials (binder type) on the pore solution chemistry and the corrosion of steel in alkaline environments," Cement and Concrete Research, vol. 89, pp. 45-55, 2016.

[41] H. Zheng, J.-G. Dai, C. S. Poon, and W. Li, "Influence of calcium ion in concrete pore solution on the passivation of galvanized steel bars," Cement and Concrete Research, vol. 108, pp. 46-58, 2018. 